\title{
SENTIDOS POLÍTICOS DO ESPAÇO ESTETIZADO: A ARQUITETURA ATRAVÉS DOS PROCESSOS DE MODERNIZAÇÃO E CONSTRUÇÃO DA CIDADANIA NA ERA GLOBAL ${ }^{1}$
}

\author{
Lígia Poggi Pereira² (Ciências Sociais, UNESP/FCL) \\ João Carlos Soares Zuin (Orientador)
}

\section{RESUMO}

O espaço urbano das cidades contemporâneas não cessa de ser modificado segundo o paradigma do capitalismo industrial e financeiro em uma nova ordem global. Além disso, a complexidade da produção social do espaço compreende uma complexidade de processos sociais, econômicos, políticos e culturais, envolvendo uma diversidade de sujeitos e grupos na dinâmica urbana. Toda alteração no sentido do espaço gera sempre novas questões para as ciências sociais. Este trabalho busca investigar as relações entre a arquitetura e a sociedade contemporânea na modernidade, analisando as questões sociais sobre o direito à cidade, o significado do espaço público e da democracia. Elementos estéticos, estilos, movimentos artísticos, da história por trás das obras são considerados em articulação com as variáveis e fatores sociológicos em métodos próprios das ciências sociais. A arquitetura enquanto fenômeno social apresenta-se em diferentes contextos, significados, usos, disputas, objetivos e funções. A relação entre a arquitetura e o espaço é um problema permanente na era moderna e, sobretudo, nas sociedades capitalistas. Pretende-se ainda recuperar uma perspectiva etnográfica, valorizando os discursos e práticas dos sujeitos na construção dos próprios objetos em suas relações de trabalho, cotidiano e práticas políticas.

Palavras-chave: Arquitetura; Direito à Cidade; Modernidade

\section{INTRODUÇÃO}

A arquitetura enquanto fenômeno social articula-se em diferentes contextos, significados e funções, das quais as mais elementares, como servir de abrigo, morada, local de trabalho, sede de atividades, estrutura material das instituições, etc. encontramse largamente diferenciadas em múltiplas outras funções, objetivos, usos e significados. Sendo criações coletivas e individuais expressam os sistemas socioculturais existentes no processo civilizatório, bem como as subjetividades que as produziram. Suas construções mantém uma estreita ligação entre os artesãos, artistas e arquitetos, a comunidade que utiliza ou demanda tais projetos, os sistemas econômicos, linguísticos e institucionais que regulamentam e dão sentido à produção e circulação de produto

\footnotetext{
${ }^{1}$ Este artigo foi formulado a partir de algumas discussões propostas em projeto de mestrado, iniciado em 2016, na linha de pesquisa Cultura, Democracia e Pensamento Social, do Programa de Pós-Graduação em Ciências Sociais da UNESP/FCL - Araraquara, sob orientação do Prof. Dr. João Carlos Soares Zuin (UNESP/FCLAr).

2 Mestranda do Programa de Pós-Graduação em Ciências Sociais da UNESP/FCL - Araraquara. Bolsista CAPES. Especialista em História da Arte pela FAAP - Ribeirão Preto. (ligia_poggi@yahoo.com.br)
} 


\section{SEMINÁRIO DE PESQUISA EM CIÊNCIAS HUMANAS - SEPECH \\ Humanidades, Estado e desafios didático-científicos \\ Londrina, 27 a 29 de julho de 2016}

culturais nas atividades cotidianas. Nas sociedades contemporâneas, dominadas pelo paradigma capitalista, há uma complexidade crescente de problemas que engendram a relação entre a arquitetura e o espaço.

Quanto à pesquisa de campo, damos importância a perspectiva etnográfica, apreendendo os discursos e práticas dos sujeitos acerca dos espaços e objetos em suas relações de trabalho, cotidiano e práticas políticas (MAGNANI, 2002). Compreender os sentidos de "coisas sociais" em seus contextos locais e pelos diferentes sujeitos, sem cair no relativismo e articulando-se com as questões trazidas pelos enfoques mais sistematizados, comparativos, da construção científica. (GEERTZ, 2013). Um dos objetivos é produzir diálogos entre questões de interesse interdisciplinar sobre a política urbana e espacial, a arte e os direitos de cidadania. Parte-se da hipótese de que a arquitetura não passa subestimada pelos atuais movimentos sociais, aparecendo de modo direto ou transversal a diversas reivindicações, apesar das diferentes formas de acesso, entendimento, práticas e objetivos relativos ao espaço. Buscamos estudar a importância da arquitetura no seio das relações de poder entre grupos, classes, nações, identidades, e enquanto expressão e produção de tensões sociais.

\section{UMA ABORDAGEM SÓCIO-ANTROPOLÓGICA E POLÍTICA DA ARQUITETURA}

O tratamento de qualidades e características estéticas, formais e de conteúdo apresenta vários caminhos. Em nossa perspectiva, é necessário que elementos estéticos, estilos, movimentos artísticos, da história por trás das obras e seus autores sejam considerados em articulação com as variáveis e fatores sociais, culturais, políticos e econômicos em métodos próprios das ciências sociais. Volta-se, assim, às práticas sociais, repertórios culturais, interações público-obra-artista, sistemas socioeconômicos, formas de sociabilidade, relações de poder e uma discussão sobre a própria construção de significados como "arte", "beleza", "sensibilidade", "estética", "conhecimento", etc. (BOURDIEU, 2007; ELIAS, 1993; GEERTZ, 2012; VÁZQUEZ, 1968). Este problema tange a construção do método e dos fatores que se darão importância à questão do conhecimento em ciências sociais.

A variedade de perfis traçados entre os agentes sociais pode evidenciar como diferentes condições socioculturais e econômicas, práticas e discursos sobre a cidade e seus recursos estéticos e arquitetônicos redesenham dialeticamente os traçados urbanos (imagens, formas, funções e significados). Inclui apreender e interpretar as relações entre classe social, idade, gênero, etnia, educação formal, entre outras variáveis sociológicas, e os elementos e configurações materiais, perceptivas e sócio-espaciais. No campo político, enfatiza-se abordar particularmente as relações da sociedade civil organizadas em movimentos sociais com o espaço urbano, patrimônio e arquitetura, como relações de pertencimento, memórias, usos cotidianos, potencialidades reflexivas, políticas e de empoderamento social.

Para efeito de síntese, aborda-se a arte nas perspectivas de construção ou produção sociocultural. Bourdieu, por exemplo, trabalha através de conceitos de campo social $^{3}$ e ação socioartística, e Elias pela compreensão de processos e forças sociais em

\footnotetext{
3 “O campo, no seu conjunto, define-se como um sistema de desvios de níveis diferentes e nada, nem nas
} 


\section{SEMINÁRIO DE PESQUISA EM CIÊNCIAS HUMANAS - SEPECH \\ Humanidades, Estado e desafios didático-científicos \\ Londrina, 27 a 29 de julho de 2016}

suas interconexões (ELIAS, 1970; 2011). Os espaços e seus objetos físicos participam ativamente do campo social, dialeticamente enquanto produtos sociais e partícipes da construção dos sujeitos, suas relações sociais e do poder sobre os corpos. Qualquer definição em torno do objeto artístico ou do lugar são articuladas a uma forma de conhecimento da realidade social. Possuem razões históricas, culturais, econômicas, sociais e políticas inseparáveis de sua concepção e recepção, mas as obras artísticas trazem sempre a problemática de certa autonomia que as transcende, seja no tempo e no lugar que foram concebidos, do trabalho de seus criadores, ou em seus significados enquanto produtos da existência humana, já que podem ser estendidos e significados “infinitamente". (ELIAS 1993; FRANCASTEL, 1973; VÁSQUEZ, 1968) A arte não é apenas uma forma característica de abordar a realidade, uma representação, é também uma criação (envolvendo intenção, invenção e um fazer-dizer) peculiar de formas e conteúdos, de conhecimento, em que seu objeto é sempre o homem em relação.

Nas perspectivas sócio-históricas e sócio-construtivistas do conhecimento e do espaço, rejeita-se definições dogmáticas, entendendo que as categorias são elas mesmas produtos sociais dos processos que pretendem explicar (ELIAS, 1970; TANNER, 2003). "Compreender não é reconhecer um sentido invariante, mas apreender a singularidade de uma forma que só existe num contexto particular" (BOURDIEU, 1994, p.159). A arquitetura extrapola o sentido espacial da arte e o sentido artístico do espaço trabalhado pelos seres humanos, comunicando-se com o ambiente material e simbólico que circunda a vida humana. Neste caso particular, a arquitetura, a arte por excelência de construir o espaço vivido, pode oferecer um caminho interessante para a investigação dos processos e lutas sociais que atravessam intimamente, extensivamente e intensivamente as cidades e as artes, em um momento histórico que nos apresenta uma multiplicidade de fenômenos políticos que tem como ingredientes indissociáveis os espaços urbanos, seus patrimônios, estéticas, objetos e projetos.

Lefebvre (2008) investigou a importância do espaço na teoria social, ao pensar dialeticamente as relações entre sociedade, espaço e tempo, dedicando-se, entre outros temas, ao estudo do cotidiano, do espaço, da modernidade, e das relações destes com o Estado. Modifica o recorte dado à categoria espaço na abordagem sociológica marxista - compreendida aqui enquanto produção social, ou seja, como realidade concreta construída dialeticamente pela ação humana. Contribui para a compreensão dos processos de reprodução das relações sociais de produção, dirigindo o olhar para questões presentes nos lazeres, no habitar, na utilização do espaço, no ambiente, na vida cotidiana. Lefebvre enfatizou que a fragmentação do espaço, pela divisão e apropriação capitalista, pode ser contraposta pela reivindicação do direito à cidade. Isto precisamente traria ao cerne da luta social a possibilidade de reverter processos de exclusão da população dos centros de produção de riquezas, dos bens culturais, dos espaços de interação, conhecimento, informação, etc., pois entende que a produção social do espaço não pode estar ausente da análise crítica dos processos de opressão efetuados pelo sistema capitalista.

$\mathrm{Na}$ análise do direito à cidade, é fundamental questionar o sentido da arquitetura e dos espaços públicos e privados, enquanto esferas de reprodução e produção sociais. Envolve discutir os processos políticos e de luta por direitos atualmente desenvolvidos

instituições ou nos agentes, nem nos atos ou nos discursos que eles produzem, tem sentido senão relacionalmente, por meio dos jogos das oposições e distinções” (BOURDIEU, 2003, p. 179). 


\section{SEMINÁRIO DE PESQUISA EM CIÊNCIAS HUMANAS - SEPECH \\ Humanidades, Estado e desafios didático-científicos \\ Londrina, 27 a 29 de julho de 2016}

nas cidades. Como compreender a questão do espaço, seus objetos e os patrimônios histórico-culturais enquanto ambientes, instrumentos e objetivos de disputas, exercendo por sua vez forças e presenças materiais, sensoriais e cognitivas? Em que medida os processos de desterritorialização e territorialização desenrolam-se na combinação de interesses locais e globais, das forças econômicas nacionais e transnacionais, com a vida local dos cidadãos?

\section{ESTÉTICA E ARQUITETURA COMO DIFERENCIAÇÃO}

As construções arquitetônicas e seus elementos estéticos podem ser valorizados e reproduzidos, participando da formação de uma cultura hegemônica e seus instrumentos de poder; ou problematizados, combatidos e transformados por diferentes grupos sociais. Nas sociedades de classes, em diferentes contextos e épocas, a arquitetura exerce o papel de representar e reafirmar as distinções entre classes e categorias sociais. Conforme há mudança nas relações entre setores dominantes e subordinados, há também uma reconfiguração simbólica, dos traços distintivos que denotam suas origens, valores, status social e identidades (BOURDIEU, 2007; ELIAS, 1993). No processo de ascensão ao poder hegemônico, a burguesia buscava imitar e se apropriar de conceitos, estilos e objetos do vestuário, das artes, das formas de linguagem, dos códigos de conduta e comportamentos da nobreza e aristocracia (ELIAS, 1993). O mesmo acontecia com os estilos arquitetônicos, buscando referências ao que era considerado nobre, luxuoso, de bom gosto, refinado, culto e distinto. As variações envolviam ainda conceitos culturais e religiosos que se traduziam na estética e padrão das casas. A casa puritana burguesa do séc. XVIII trazia consigo os ideais de ascetismo, racionalidade e pragmatismo (WEBER, 2004), que se traduziam em formas racionais, mobiliário rústico e tradicional, sobriedade, valorização da privacidade, pouca ornamentação, concomitantemente denotando status e prestígio social.

Em contraste, observa-se a casa burguesa do fin-de-siécle, em seus excessos, ecletismo, na tendência ao "kitsch" (BENJAMIM, 1993) e ostentação, na abundância de referências históricas e produtos - tapeçarias turcas, mobiliário estilo rococó, porcelanas orientais, pinturas acadêmicas, fotos de família, bibelôs, artigos estrangeiros, livros, pianos, preenchendo o espaço privado de uma necessidade crescente de consumo, novidade, conforto e referências históricas. Objetos e acúmulos de bens privados combinados em um contexto particular produziam novos sentidos comunicativos e funcionais; representam os valores desta burguesia já estabelecida, carregando o espaço doméstico e público de seus símbolos de poder e cultura, afiliações, história, desejos, valores afetivos. A cidade modifica-se para atentar as demandas desta nova classe, modificando o cenário urbano para dar passagem a um novo estilo de vida. "O Governo quis que as ruas pertencendo ao povo de Paris ultrapassassem em magnificência os salões dos mais nobres soberanos" (BENJAMIN, 2006). Conforme ascendia socialmente e economicamente, tornou-se imperativo construir narrativas, símbolos e comportamentos próprios, signos que evidenciassem sua autonomia em relação à antiga nobreza e também em relação aos trabalhadores e camponeses das classes baixas ${ }^{4}$

\footnotetext{
4 A mesclagem de elementos populares e nobres pode ser analisada em um jogo no qual agiam a necessidade de diferenciação e domínio sobre o proletariado, a assimilação de traços da nobreza e a
} 


\section{SEMINÁRIO DE PESQUISA EM CIÊNCIAS HUMANAS - SEPECH \\ Humanidades, Estado e desafios didático-científicos \\ Londrina, 27 a 29 de julho de 2016}

apesar de manterem-se atados a certas tradições e identidades nacionalistas. (DEMPSEY, 2010; ELIAS, 1993)

A estética das cidades modernas traz a história de ascensão da burguesia, do Estado-Nacional e da Igreja, desde as estátuas, os letreiros, os nomes das ruas, os grandes casarões, as igrejas cristãs, até chegar aos shoppings centers, as enormes estruturas das multinacionais, os edifícios esplendorosos, os muros e cercas que separam os indivíduos, as classes, as regiões. Câmeras de vigilância, segregação urbana, arranha-céus empresariais, condomínios e favelas que crescem sobre áreas de proteção ambiental. O pixo, o grafite, as artes de rua tornam-se novas expressões extremamente modernas, inseparáveis do contexto em que surgiram, mas trazem as contradições do mundo globalizado. Museus de arte e patrimônios dos séculos XIX e XX são reivindicados por minorias sociais do século XXI, para exporem em espaços normatizados a arte que é produzida na liberdade das ruas e é inseparável da performance do público. Artistas que cresceram na marginalidade, nos bairros periféricos dos países subdesenvolvidos viajam o mundo levando a arte e a realidade locais, apesar de uma intensa negação em seus países de origem. As tensões atravessam a arte e a arquitetura por todos os lados, dos centros culturais, aos espaços expositivos, à apropriação da cidade aberta.

Um dos problemas que se levanta é como analisar e interpretar estes movimentos de construção e destruição da arquitetura e do espaço os quais acontecem em contexto local, e a relação com os fenômenos globais. Nesta relação local-global, as imagens e objetos arquitetônicos participam ao nível de construção de sentidos que atravessam fronteiras e culturas e reelaboram as formas de percepção e interpretação não apenas do espaço, mas das relações sociais e saberes sobre a cidade e o mundo onde se vive.

\section{MODERNIZAÇÃO E CAPITALISMO: SENTIDOS DETERMINANTES NA PRODUÇÃO ARQUITETÔNICA}

Evidentemente, do século XIX em diante, há uma alteração significativa das questões urbanísticas e arquitetônicas - transformados em projetos de modernização (BENEVOLO, 1976; SECCHI, 2013) - que incluíam a reestruturação do território segundo os interesses de acumulação de capital, de formação de massas de trabalhadores livres, privatização dos meios de produção e circulação de produtos, pessoas e informações. $\mathrm{O}$ avanço tecnológico propiciava novos materiais (como ferro, aço, rede elétrica), conceitos e técnicas de construção e o urbanismo torna-se questão central para o avanço do novo sistema de produção, novas sociabilidades e mentalidades. A cidade moderna segue um plano de orientação capitalista industrial,

apropriação de muitos de seus instrumentos de capital econômico e simbólico - estas sínteses condicionavam a questão do gosto, da educação religiosa, intelectual, científica e artística. Pairava no ar um idealismo: o caminho de progresso de suas origens humildes para a elite dominante, a derrubada dos antigos poderes nobiliárquicos e a possibilidade do homem livre em realizar-se através do livre-mercado e cuidado de si, tomado como condição para uma sociedade virtuosa. O ideal de progresso modificou o espaço da casa, do trabalho e da vida pública, separando o homem burguês cada vez mais de suas origens plebeias e apagando ou retrabalhando os sinais do Antigo Regime. 


\section{SEMINÁRIO DE PESQUISA EM CIÊNCIAS HUMANAS - SEPECH \\ Humanidades, Estado e desafios didático-científicos \\ Londrina, 27 a 29 de julho de 2016}

mas também inclui a reflexão sobre si mesma, a autocrítica, o vanguardismo, o desejo de modificar o destino de seus habitantes, onde transita a diferença, a inquietude, a revolta em relação a um projeto universal (GOHN, 2009). Os movimentos sociais e artísticos incorporam ativamente as operações de auto-reflexividade. O processo de reflexão e crítica da sociedade moderna de seus próprios paradigmas é concebido por alguns autores (BECK; GIDDENS; LASH, 2012) como tendo chegado a uma radicalidade nas últimas décadas 5 .

John Ruskin (1810 - 1900) é um exemplo histórico interessante. Sua extensa e influente obra sobre pintura, arquitetura, política e economia teve papel fundamental para o Movimento de Artes e Oficios e do Art Nouveau ${ }^{6}$, suscitando transformações no design industrial e arquitetônico. Ruskin é um autor que representa a tensão entre o moderno e o tradicional, a indústria e o ofício artesanal, "contrariando as certezas modernistas amplamente difundidas a partir dos anos 30 sobre o anacronismo e a irrelevância do trabalho artesanal no mundo industrial moderno". (PAIM, 2000, p.26). A ornamentação, por exemplo, não era apenas uma questão estritamente estética; era intrinsecamente associada a questões econômicas, morais e religiosas. Ele foi um crítico da operação do capitalismo industrial no processo de anulação do caráter de trabalho da obra, e da relação artesão-obra-público e as consequências deste processo. $\mathrm{O}$ trabalho humano estava na realização da forma - enquanto dimensão comunicativa, de criação de consciência acerca da atividade que a concebeu. Sua análise vê os ornamentos enquanto formas produtoras de sentidos e percepções específicas, podendo reproduzir ou resistir aos efeitos da alienação, reprodutibilidade e funcionalidades econômicas e simbólicas que o capitalismo industrial promovia sobre o mundo. Desde o Renascimento as artes e arquitetura vão tornando-se assunto cada vez mais dominado por especialistas e elites - separando o artista do artesão, até chegar à separação mais nefasta para a arte entre designer e operário -, enquanto os efeitos de "perfeição" cada vez mais acentuados pelo desenvolvimento tecnológico retiram as imperfeições, desvios e particularidades da artesania que lhe davam aos objetos o valor de criatividade e liberdade (PAIM, 2000).

O espaço urbano moderno, além de moradia e espaço de vivência, é fábrica, espetáculo, comunicação e mercado. O processo de alienação e o fetichismo estão presentes na arquitetura e no espaço urbano, já que são imanentes à estrutura social

\footnotetext{
${ }^{5}$ [...] el industrialismo como sistema aparentemente independiente y autónomo há hecho estalar su lógica y sus fronteras y ha entrado em um processo de autodisolución. Este giro radical caracteriza la actual fase de la modernización en la que ésta se hace reflexiva. En vez de seguir explorando las diversas sendas y potenciales de la modernidad industrial, la modernización desmenuza ahora los princípios e instituciones social, política y culturalmente básicos de la sociedad industrial nacional y abre paso a nuevos potenciales de oposición a la misma. Así pues, el processo de modernización reflexiva va de la sociedade industrial nacional a la equívoca, aún indeterminada sociedad mundial. (BECK, 2008, p. 286)

${ }^{6}$ Movimento Arts and Crafts, cujo maior expoente foi William Morris (1834-1896), arquiteto, designer e sociólogo. Tentou desenvolver e aplicar as ideias de Ruskin, aplicando conceitos e métodos do ofício artístico e artesanal à produção industrial e comercial. Percebe, no entanto, que a Revolução Industrial imprime um ritmo e sistema produtivo impossível de ser conciliado com a técnica e proposta artesanal. O Art Nouveau é um movimento posterior inspirado pelo arts and crafts, reunindo referências da arte oriental, medieval, da indústria, mesclando inspirações da natureza, com seus temas, suas formas vegetais, sinuosas e orgânicas, do exótico, do artesanato minucioso e das novas técnicas e conceitos advindos da indústria. Influenciou as artes gráficas, a arquitetura, a decoração, o design, a propaganda, tendo marcado a arte da passagem do século XIX ao XX.
} 


\section{SEMINÁRIO DE PESQUISA EM CIÊNCIAS HUMANAS - SEPECH \\ Humanidades, Estado e desafios didático-científicos \\ Londrina, 27 a 29 de julho de 2016}

capitalista. Como outras mercadorias produzidas, mediam as relações sociais a partir de determinados condicionantes econômicos e de poder - ocultando muitas vezes o caráter desigual e opressor das relações de produção, passando a ocupar o centro das atenções nas relações de produção e troca. O modelo da fábrica, do presídio, da fortaleza, da torre de vigilância mantém permanências, apesar de inumeráveis movimentos e estilos arquitetônicos/urbanísticos novos.

$\mathrm{Na}$ lógica tecnicista e racional, voltada ao incremento da eficiência produtiva, da máxima extração de lucro, a cidade é organizada para atender aos interesses do capital e consumo. Torna-se extensão da fábrica e propaganda ${ }^{7}$, mas na medida que se renova, tornando-se mais flexível, virtual, transnacional, móvel - acompanhando o fluxo de capitais, desterritorialização e inovação constantes - tem uma materialidade que as mantém atadas a padrões urbanísticos encontrados por toda parte. Conflitos e contradições preenchem os cenários urbanos, produzindo-se e reproduzindo-se no espaço urbano, em seus desenhos, símbolos e objetos, modelados em estilos e padrões arquitetônicos (CACCIARI, 2009; GREGOTTI, 2011; ORTIZ, 1992; SECCHI, 2013). O domínio do privado representa inúmeros problemas ao planejamento urbano e ao meio ambiente, que observa o espraiamento do espaço urbano, a falência dos sistemas de transporte - que faz irromper em toda parte "mobilização social pela mobilidade urbana"-, o alto consumo de combustíveis fósseis e matéria-prima, altos índices de acidentes de trânsito, crescimento desordenado, carência de áreas verdes, redução e precarização dos espaços públicos, prevalência dos interesses privados e corporativos sobre o interesse público. A especulação imobiliária e os modelos dominantes de política urbana - ou da sua falta e substituição por lógicas de mercado - esvaziam os centros urbanos e coletivos alimentando os espaços de segregação e desigualdade, o descaso com o patrimônio histórico-cultural e espaços públicos populares. $\mathrm{O}$ afastamento acontece em paralelo aos processos de massificação e mercantilização das manifestações artístico-culturais, e a marginalização ou elitização de esferas produtivas.

Engenheiros, arquitetos, urbanistas, geógrafos, artistas, etc. dividem-se em elites e espaços sociais bem delimitados entre as categorias profissionais técnico-artísticas, de acordo com seus lócus na estrutura socioeconômica, nas instituições, no Estado, no sistema de mercado das artes e arquitetura. Neste sentido, vale uma investigação da circulação tanto dos diferentes discursos e papéis que os arquitetos e outros agentes envolvidos nas questões urbanísticas e arquitetônicas engendram na sociedade, observando um prisma mais colorido da realidade social, econômica e política de suas ações em diferentes contextos e campos sociais. Quais aqueles que buscam soluções para problemas urbanos e coletivos, para a função social e transformadora da arte e

\footnotetext{
${ }^{7}$ [...] parece que nesse mundo dominado pela informação a arte deve cumprir um novo papel. De maneira idêntica a outras instâncias sociais, ela busca transmitir algum tipo de ideia. É essa preponderância da mensagem que leva a arquitetura a se aproximar da publicidade. Ou como comenta Venturi: "Para o arquiteto ou o desenhista urbano, a comparação de Las Vegas com outros mundos ou zonas de prazeres por exemplo, Marienbad, Alhambra, Xanadu, Disneylândia - sugere que o essencial para uma imagem arquitetônica dessas zonas é a leveza, a qualidade de ser um oásis dentro de um contexto hostil, um simbolismo pesado e a habilidade de mergulhar o visitante em um novo papel. Por três dias, ele pode imaginar-se um centurião no Caesars Palace, um ranger no Frontier ou um ricaço no Riviera, ao invés de ser um vendedor em Des Moines, lowa, ou um arquiteto em Haddon-field, New Jersey". A passagem é inequívoca. A arquitetura adquire uma função de persuasão e não só de orientação, seduzindo o passante; ela integra os desejos à sociedade de consumo. (ORTIZ, 1992)
} 


\section{SEMINÁRIO DE PESQUISA EM CIÊNCIAS HUMANAS - SEPECH \\ Humanidades, Estado e desafios didático-científicos \\ Londrina, 27 a 29 de julho de 2016}

arquitetura? Como relacionam-se com outros grupos na questão dos direitos à cidade?

\section{INSEGURANÇA E EXCLUSÃO: IMPEDIMENTOS À CIDADANIA VIVIDA NO ESPAÇO DA CIDADE}

A insegurança e o medo participam da construção da vida nas cidades contemporâneas. Fenômenos comuns à vida nos grandes e médios centros urbanos - a sensação de ameaça constante e a construção de mecanismos de proteção e vigilância. A competitividade e individualismo substituíram relações de solidariedade e cooperação. Na busca por culpados e inimigos, elabora-se a figura do estrangeiro, junto ao pobre, ao negro e ao morador de periferia - quando não todos representados pelas mesmas pessoas. Pensar o mundo moderno e as lutas democráticas precisa passar por um olhar sobre os processos migratórios, as políticas de integração ou expulsão dos trabalhadores e imigrantes, as relações entre Estado e sociedade civil, as novas questões de identidade, o papel desempenhado pelos imigrantes e outras categorias plurais na extensão e realização de direitos coletivos (AMENDOLA, 2010; GREGOTTI, 2011; SASSEN, 2013; TODOROV, 2011). Em um cenário de desigualdades, o espaço é remodelado segundo as buscas incessantes por segurança, delimitando distinções, inclusões e exclusões entre grupos (SECCHI, 2013). A marginalização é estrutural, condenando populações a um estado de desemprego e desintegração permanente - são pessoas tornadas supérfluas, descartáveis (BAUMAN, 2005).

Tais processos culturais esvaziam o exercício da cidadania, o direito de morar, circular, pertencer, participar e decidir o destino comum de uma sociedade. Confinados aos grandes bairros periféricos, o local de residência torna-se também estigma social. A segregação social é reforçada por políticas de planejamento urbano, livre mercado de imóveis e especulação imobiliária. Comunidades são transportadas ou destruídas para ceder lugar a centros empresariais, grandes avenidas, aeroportos, bairros nobres ou condomínios. Muros são erguidos, separando os territórios, os grupos sociais, as classes e as funções da cidade, impondo novos problemas ao social e à gestão pública. $\mathrm{O}$ desenho das cidades é incessantemente transformado, mas a desigualdade social é globalizada, reproduz-se em todos os locais, em semelhantes os modelos civilizatórios e as grandes metrópoles (BAUMAN, 2005; BECK, 2008; GREGOTTI, 2011; TODOROV, 2011). Não há como prever o espaço urbano em modelos clássicos: a indústria, os serviços, o ambiente de trabalho, foram disseminados e estão em constante mutação, assim como a especulação e o capital flexível movem as relações centroperiferia (AMENDOLA, 2010). É uma estética global da insegurança, do consumo, da velocidade e da desigualdade que define a forma como se faz cada construção.

A arquitetura passa diretamente a imagem do afastamento da vida pública em guetos, favelas, casas e prédios cercados e murados. Os condomínios salientam a legitimidade da exclusão, da separação, da proibição de circulação dos "outros", do distanciamento dos assuntos da cidade. Seu projeto recria um ambiente de pureza/pobreza estética, funcional e sociocultural. Os espaços de consumo (shoppings centers, academias, clubes, restaurantes) são os pontos de encontro das classes mais altas, permeados pela lógica de consumo, privilégio, propriedade privada, status e semelhança, onde conflitos sociais são mascarados ou afastados. A ocupação destes espaços por indivíduos "não pertencentes", "estranhos" ou "invasores" - estrangeiros, 


\section{SEMINÁRIO DE PESQUISA EM CIÊNCIAS HUMANAS - SEPECH \\ Humanidades, Estado e desafios didático-científicos \\ Londrina, 27 a 29 de julho de 2016}

mendigos, jovens periféricos, homossexuais, pobres, etc. é motivo de estranhamento, constrangimento e notícia. A socialização perpetuada entre os iguais é promovida pela organização do espaço urbano e arquitetônico. Como outra arquitetura atuaria promovendo a participação coletiva?

\section{CONSIDERAÇÕES FINAIS}

O espaço público é necessário para uma experiência compartilhada - condição para o entrosamento e a comunicação entre os habitantes. Como pode-se incorporar a arquitetura na resposta a estes problemas? Atenta-se ao papel fundamental das minorias em construir sociedades mais democráticas - afinal, são as minorias, os pobres, os imigrantes que constituem um enorme contingente de forças sociais que pressionam os limites cívicos, pela multiplicidade de atores, grupos e comunidades que buscam participação política, e não uma mera submissão à lógica do Estado-Nação e identidades estabelecidas (GOHN, 2009; SASSEN, 2013; SECCHI, 2013).

Segundo Cacciari (2009), pedimos coisas diferentes a cidade, cultivando dois ideais, dois sentimentos - da cidade enquanto lugar bom para os negócios, para o trabalho, local da modernidade, da tecnologia, dos capitais, da diversidade, da comunicação. Por outro lado, buscamos nostalgicamente a vida não-urbana, o idílio campestre, a fuga da cidade, a volta à tribo, um ideal de vida comunitária e romântica. A tensão entre o lugar de otium e de negotium. Entre os séculos XV e XX houve uma destruição massiva de tudo o que impedia o movimento dos negócios, de forma mais ou menos violenta ou sistemática. Atualmente, quem se preocupa em manter a história, a memória, as reminiscências da cidade antiga, e transformar estes espaços em uma comunicação entre o presente e o passado? O que pretendem fazer destes espaços, e como isto tem razões sociais, políticas e culturais próprias?

Um dos grandes desafios contemporâneos é refletir sobre o sentido da cidade e dos projetos urbanísticos e arquitetônicos. Este sentido almeja a participação coletiva para além de vanguardismos ou tradicionalismos de cima para baixo. Há de se aproximar a leitura das obras e projetos arquitetônicos e urbanísticos com as mobilizações sociais e ações político-culturais, observando como os sujeitos mobilizam, apropriam e transformam discursos, ferramentas, técnicas, obras ou espaços, em integração aos processos de empoderamento social, ressignificação de relações com o espaço urbano e social, e expansão dos direitos à cidade.

\section{REFERÊNCIAS}

AMENDOLA, Giandomenico. Tra Dedalo e Icaro: La nuova domanda di città. Roma Bari: Laterza \& Figli, 2010.

BAUMAN, Zygmunt. Confiança e medo na cidade. Rio de Janeiro: Zahar, 2005.

BECK, Ulrich. La sociedad del riesgo mundial. Barcelona: Paidós, 2008.

BECK, Ulrich; GIDDENS, Anthony \& LASH, Scott. Modernização reflexiva. 


\section{SEMINÁRIO DE PESQUISA EM CIÊNCIAS HUMANAS - SEPECH \\ Humanidades, Estado e desafios didático-científicos \\ Londrina, 27 a 29 de julho de 2016}

Política, tradição e estética na ordem social moderna. São Paulo: Ed. Unesp, 2012.

BENEVOLO, Leonardo. História da arquitetura moderna. São Paulo: Perspectiva, 1976.

BENJAMIN, Walter. Passagens. Belo Horizonte: Editora da UFMG, 2006.

. Rua de mão única. São Paulo, Brasiliense, 1993.

BOURDIEU, Pierre. A distinção: crítica social do julgamento. São Paulo: Edusp, 2007.

O poder simbólico. Rio de Janeiro: Bertrand Brasil, 2003.

CACCIARI, Massimo. A cidade. Barcelona: Gustavo Gili, 2010.

DEMPSEY, Amy. Estilos, escolas e movimentos: guia enciclopédico da arte moderna.

São Paulo: Cosac-Naify, 2010.

ELIAS, Norbert. Introdução à Sociologia. Lisboa: Edições 70, 1970.

O Processo Civilizador: Formação do Estado e Civilização. Rio de Janeiro: Jorge Zahar Editor, vol. 2, 2011.

FRANCASTEL, Pierre. A realidade figurativa. São Paulo: Editora Perspectiva, 1973.

GEERTZ, Clifford James. O saber local: novos ensaios em antropologia interpretativa. Petrópolis:Vozes, 2013.

GOHN, Maria da Glória. Novas teorias dos movimentos sociais. São Paulo: Loyola, 2009.

GREGOTTI, Vittorio. Architettura e postmetropoli. Torino: Giulio Einaudi, 2011.

LEFEBVRE, Henri. Espaço e política. Belo Horizonte: Ed. da UFMG, 2008.

MAGNANI, José Guilherme Cantor. De perto e de dentro: notas para uma etnografia urbana. Rev. bras. Ci. Soc., São Paulo, v. 17, n. 49, p. 11-29, Junho, 2002.

ORTIZ, Renato. Reflexões sobre a pós-modernidade: o exemplo da arquitetura. Revista Brasileira de Ciências Sociais, n. 20, out. 1992.

PAIM, Gilberto. A beleza sob suspeita: o ornamento em Ruskin, Lloyd Wright, Loos, le Corbusier e outros. Rio de janeiro: Jorge Zahar, 2000.

SASSEN, Saskia. Inmigrantes e ciudadanos: de las migraciones massivas a la Europa fortaleza. México/Espanha: Siglo Veintiuno Editores, 2013. 
SECCHI, Bernardo. La città dei ricchi e la città dei poveri. Roma-Bari: Laterza, 2013.

TANNER, Jeremy (Org). The sociology of art: a reader. London: Routledge, 2003.

TODOROV, Tzvetan. Muros caídos, muros erigidos. Buenos Aires: Katz editores, 2011.

VÁZQUEZ, Adolfo Sánchez. As ideias estéticas de Marx. Rio de janeiro: Paz e Terra, 1968.

WEBER, Max. A ética protestante e o "espírito" do capitalismo. São Paulo: Cia. das Letras, 2004. 